2. Обзор тенденций на глобальном и Российском фармацевтическом рынке / отчет подготовлен при поддержке Рынка Инноваций и Инвестиций (РИИ) московской биржи и Фонда развития промышленности (ФРП). [Электронный ресурс] Режим доступа: https://docplayer.ru/32484978Obzor-tendenciy-na-globalnom-i-rossiyskom-farmacevticheskom-rynke.html (дата обращения 04.04.2021)

3. 医療関係者の確認 $\mid$ MSD Connect [Электронный pecypc] Режим доступа: https://www.msdconnect.jp/disclaimer.xhtml?request_url=www.msdconnect.jp/medinfo/productslist.xht $\mathrm{ml} \#$ (дата обращения 04.04.2021)

4. Укрепить и развить успех в деле искоренения СПИДа: на старт, внимание, марш! [Электронный peсурс] Режим доступа: https://www.unaids.org/ru/Global_AIDS_strategy_process (дата обращения 17.04.2021)

\title{
Махрова М.М. \\ Цифра и текст: особенности числового обозначения в русскоязычных инфографиках разных видов
}

Владимирский государственный университет им. А.Г. и Н.Г. Столетовых (Россия, Владимир)

doi: 10.18411/lj-05-2021-275

\section{Аннотация}

Несомненный интерес для исследования представляют структура и содержание современной русскоязычной инфографики как актуального явления информационного пространства XXI века. До настоящего момента специалистами с точки зрения лингвистической науки не рассматривалось соотношение числа и текста в инфографиках разного вида, данный аспект выбран для рассмотрения в настоящем исследовании.

Ключевые слова: инфографика, рейтинг, статистика, рецепт, хронология, число, цифра, текст

\section{Abstract}

The structure and content of modern Russian-language infographics as an actual phenomenon of the information space of the XXI century are of undoubted interest for the study. Until now, experts from the point of view of linguistic science have not considered the ratio of numbers and text in infographics of different types, this aspect is chosen for consideration in this article.

Keywords: infographics, rating, statistics, recipe, timeline, number, figure, text

Любопытное явление современного информационно-коммуникационного пространства - инфографика на протяжении последних десятилетий привлекает внимание отечественных и зарубежных специалистов, в их числе В. Лаптев, Р. Крам, М. Смикиклас. Существуют разные подходы к изучению и определению данного понятия. На наш взгляд, инфографика представляет собой креолизованный текст, включающий в себя элементы разных знаковых систем.

Интересным аспектом для лингвистического анализа представляется соотношение слова и цифры при числовых обозначениях в инфографиках разных видов. Попыток лингвистического исследования соотношений цифровых и буквенных обозначений в инфографических текстах до настоящего момента не предпринималось, что обуславливает актуальность предлагаемой работы.

Целью настоящего исследования является описание наиболее типичных случаев числового обозначения информации в структуре современных русскоязычных инфографик. Автор ставит перед собой следующие задачи: проследить, как функционирует цифра в креолизованном тексте, установить закономерности между особенностями числового обозначения информации и конкретным видом инфографики. 


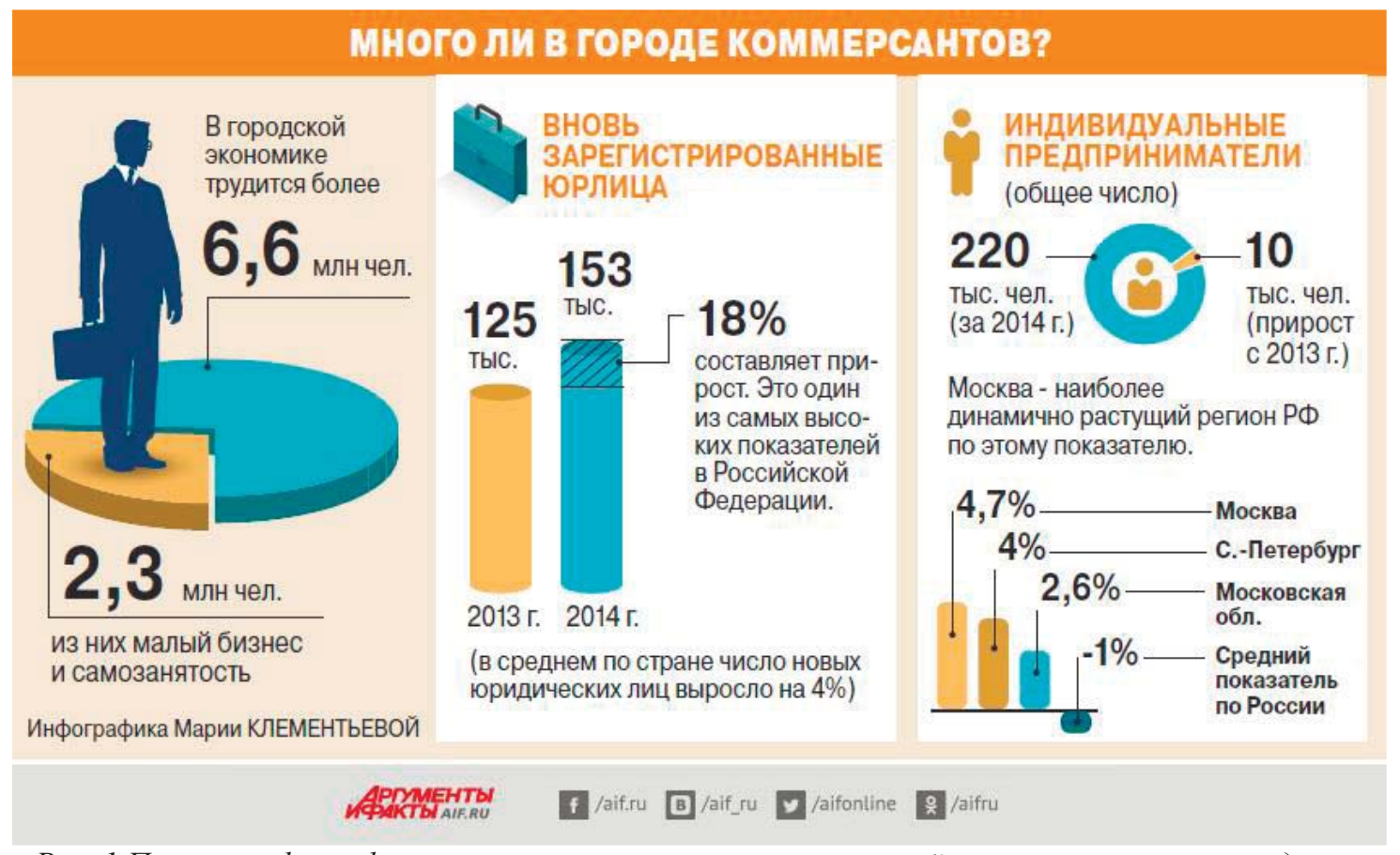

Рис. 1 Пример инфографики смешанного типа с элементами рейтинга и статистики издания «Аргументы и факты»»

Нами были рассмотрены 500 статичных (без изменяющихся аудио/видео эффектов) русскоязычных инфографик, представленных в открытом доступе.

В рекламном и публицистическом дискурсах, в рамках которых, как правило, рассматривается явление инфографики, сложились закономерности и правила обозначения числа в текстах. Исследователь К.М. Накорякина выделяла следующие наиболее типичные особенности: числа первого десятка обозначаются словами, двузначные и многозначные числа - цифрами [3]; если в публицистическом тексте встречается падежная форма (количественно-именное сочетание), число обозначается словами. Следует отметить, что в случае, когда автор хочет подчеркнуть точное числовое значение, то передаёт его на письме цифрой. Кроме того, цифровое обозначение информации выполняет в тексте аттрактивную функцию. В проанализированных нами примерах инфографик встречается смешанная запись (буквенная или числовая). Отметим, что соотношения большого количества цифр и данных лежат в основе инфографики любого вида, однако можно выделить виды русскоязычных инфографик, в которых числовой компонент можно считать необходимой составляющей.

Числовые обозначения (текстовые и цифровые), на наш взгляд, являются обязательными в инфографиках-рейтингах, инфографиках-рецептах, инфографикахстатистических схемах, инфографиках-хронологиях.

Инфографики-рейтинги передают числовые показатели и большие объёмы данных, выстроенные в градационный ряд. В большей степени в инфографикахрейтингах встречается цифровое обозначение пунктов списка или подборки. В словосочетаниях с именем существительным числовой показатель обозначается цифрой, ср., например, 1 место.

Количественно-именных сочетаний в проанализированных нами примерах инфографик-рейтингов не встречалось. Интересной особенностью, отмеченной нами в некоторых заголовках инфографик данного типа, стало избыточное сочетание числового и текстового обозначения количества, cp., например, 5 Пятёрка лучших показателей, что может быть обусловлено целью автора привлечь внимание читателей к содержанию инфографики. 


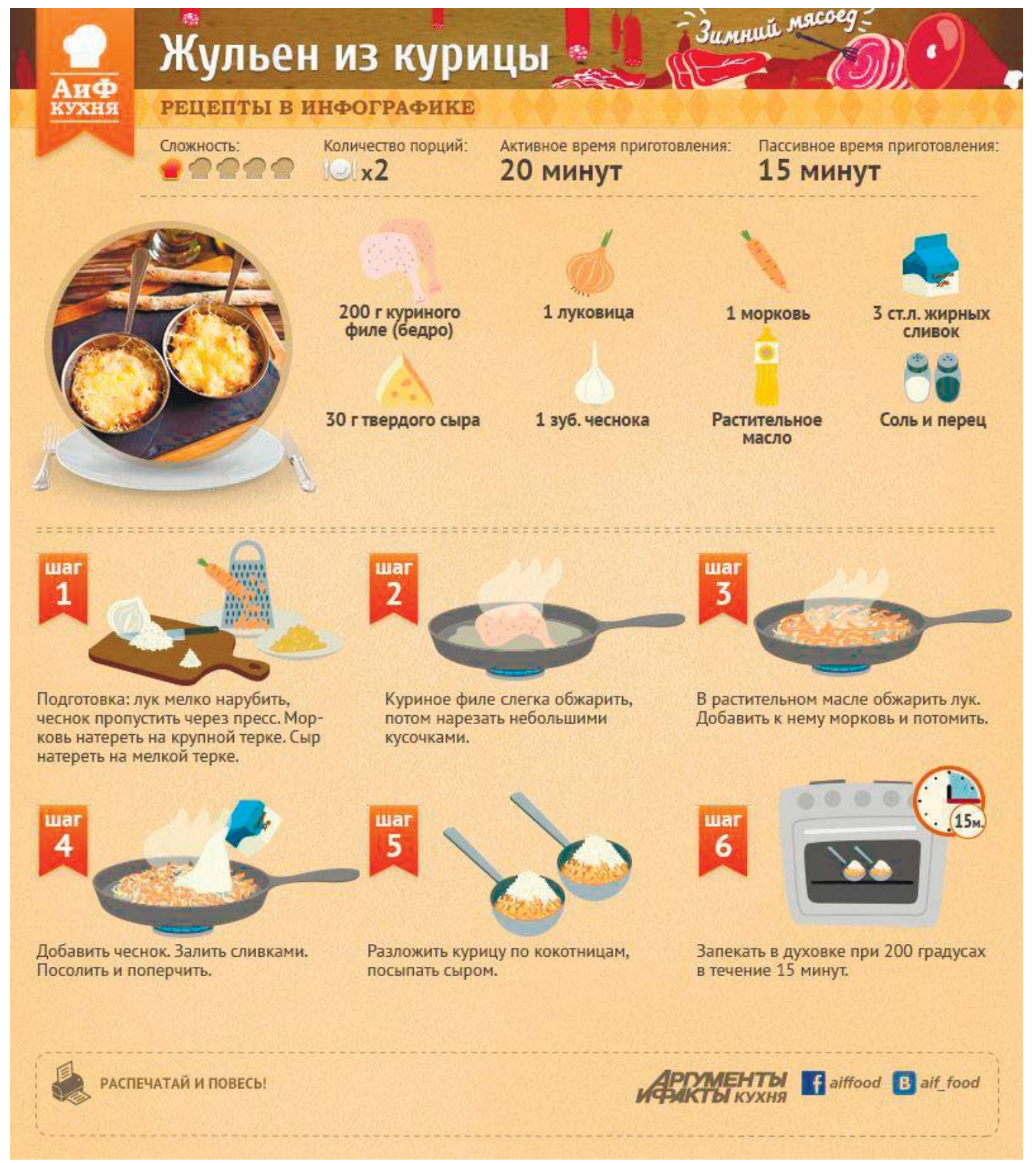

Рис. 2 Пример инфографики-рецепта издания «Аргументы и фактыл»

Инфографики-статистики раскрывают количественные соотношения и зависимости, в отличие от инфографик-рейтингов, по структуре и содержанию, статистики наиболее аналитичны. Цифровое обозначение данных по содержательности в инфографиках-статистиках превалирует над текстовым, в контексте даётся минимум пояснений, так как наиболее показательны с точки зрения информативности именно числовые обозначения ср., например, словосочетание 76\% cmapme 60 лет. Дроби в проанализированных нами инфографиках-рейтингах и инфографиках-статистиках встречались в виде десятичной записи, ср., например, 4,7\% Москва.

В инфографиках-рецептах, демонстрирующих процесс приготовления блюда или напитка, наибольший объём числовых обозначений сгруппирован в тематическом блоке ингредиенты. Данный вид, на наш взгляд, наиболее интересен с точки зрения соотношения числа и текста. Цифры передают объём продуктов и веществ, время приготовления, и сочетаются с единицами измерения веса, времени, количества объектов. Ср., например, 1 кг спелых помидоров, пассивное время приготовления 4 часа 
10 минут, 1 столовая ложка уксуса. Отметим, что в проанализированных примерах, в инфографиках-рецептах наблюдается тенденция цифрового, а не текстового обозначения числовых значений объектов ср., например, Хлеб разломить на 4 части, что объясняется, на наш взгляд, стремлением автора к конкретности данных и дополнительным привлечением внимания адресата инфографики. Отметим, что в некоторых инфографиках прослеживается избыточность данных ср., например, замесить эластичное тесто и поставить в холодильник на 1 час. В контекстуальном примере единица измерения времени час сама по себе даётся в единичном значении и цифровое дополнение оказывается лишним. В тематическом блоке ингредиенты употребление цифрового обозначения количества продукта, которое стоит в форме единственного числа, что объясняется необходимостью максимально конкретного пояснения вместо цеедра лимона, в инфографике фиксируется цедра 1 лимона. В падежном сочетании, обозначающем приблизительное время приготовления блюда, единица измерения передаётся словом без цифрового дополнения, что соответствует норме современного русского языка: тушить около часа. Единицы измерения температуры приготовления в инфографиках обозначаются цифрой запекать жульен $в$ духовке при 160 С до золотистой корочки.

Дробные числа в проанализированных нами инфографиках-рецептах передаются цифрами, а единицы измерения даются в сокращении 1/2 ч.л. жидкой ванили, ч.л. в данном случае чайной ложки. В некоторых примерах инфографик-рецептов для привлечения внимания читателя числовые обозначения дублируются в визуальном и в текстовом компоненте. Ср, например, рис. 1, 50 минут и $160 C$ встречаются дважды: в изображении и текстовом пояснении. Приблизительность количества передаётся инверсивным порядком слов ср., например, Bыключить и дать настояться минут 20; печь 50 минут; дать салату пропитаться часа 3-4. На наш взгляд, автор сам определяет, какие факторы в приготовлении блюда являются наиболее существенными и требуют предельной конкретики, а в каких пунктах возможна вариативность. Отметим ещё одну интересную особенность, числовое обозначение количества, в некоторых примерах инфографик-рецептов, обозначается с помощью визуализации, ср., например, количественно-именное сочетание заменяется абстрактным изображением считаемого объекта, например, три картофелинь в одной из проанализированных инфографик представляют собой сочетание лексемы картофель и изображений трёх картофельных клубней.

Инфографики-хронологии раскрывают динамику развития временных отрезков крупного исторического события или целой эпохи. Наиболее частотно для инфографикхронологий сочетание числа, названия месяца и лексемы год в постпозиции, ср., например, 9 мая 1945. Дробных чисел в проанализированных нами примерах инфографик-хронологий не встретилось, что объясняется спецификой данного вида инфографики, отражающего завершённые целые хронологические фрагменты.

Таким образом, сочетания цифры и текста в русскоязычных инфографиках разных видов варьируются в зависимости от замысла автора и остаются интересной сферой для дальнейшего лингвистического исследования. Отдельные текстовые элементы часто дополняются или заменяются изображением. Наиболее объёмно числовые данные представлены в инфографиках-рейтингах, инфографиках-рецептах, инфографиках-статистических схемах, инфографиках-хронологиях. Показательно, что в инфографиках данного вида цифровая запись чисел превалирует над текстовой, что объясняется необходимостью точно, конкретно и кратко передать информацию аудитории и привлечь внимание к цифровым показателям в содержании конкретной инфографики.

$$
* * *
$$

1. Крам Р. Инфографика. Визуальное представление данных. - СПб.: Питер, 2015. - 383 с. 
2. Лаптев В. Русская инфографика. - СПб.: Издательско-полиграфический центр Политехнического университета, 2018. - 399 с.

3. Накорякова K. M. Цифра в публицистическом тексте. URL: http://www.gramota.ru/biblio/magazines/gramota/28_39

4. Смикиклас М. Инфографика: коммуникация и влияние при помощи изображений. - СПб: Питер, 2014. $-150 \mathrm{c}$.

\section{Молчанова С.Е., Лысенко Н.А. \\ Основные стилистические функции повтора в современных английском и немецком языках (на материале художественного стиля)}

РФ ФГБОУВО «Российский государственный университет правосудия» (Россия, Ростов-на-Дону)

doi: 10.18411/lj-05-2021-276

\section{Аннотация}

В статье выявляется частотность употребления и основные стилистические функции различных видов повтора в современном художественном стиле английского и немецкого языков. Рассматриваются функции таких видов повтора, как синтаксический (многосоюзие, синтаксический параллелизм, подхват, анафора, эпифора, синтаксическая тавтология, рамочная конструкция), лексический (простой, синонимический, плеоназма), морфологический (корневой, аффиксальный). Выявляются сходства и различия в употреблении и функционировании повтора в английской и немецкой художественной прозе.

Ключевые слова: повтор, различные виды повтора, стилистические функции повтора, художественный стиль.

\section{Abstract}

The article deals with the frequency of usage of different types of repetition as a stylistic device and their main stylistic functions in the belles-letters style of modern English and German. The functions of the following types of repetition are considered: syntactic (polysyndeton, syntactic parallelism, anadiplosis, anaphora, epiphora, syntactic tautology, pleonasm), lexical (simple, synonymic, pleonasm), morphemic (root, affixal). Similarities and differences of usage and functioning of repetition in English and German prose are revealed.

Key words: repetition, different types of repetition, stylistic functions of repetition, belles-letters style.

Повтор как стилистический приём служит одним из основных средств реализация авторского замысла. Он способствует усилению эмоциональности и экспрессивности высказывания, является способом выражения субъективнооценочного отношения к предмету речи, индивидуализации и интенсификации речи, одним из важнейших средств побуждения, воздействия на адресата.

Проведённый анализ примеров нашей выборки показал, что в современных художественных произведениях английских и американских авторов встречаются следующие виды повтора: синтаксический (50\%), лексический (32\%) и морфемный $(18 \%)$.

Частотность употребления различных видов синтаксического повтора распределяется следующим образом: полисиндетон (23\%), синтаксический параллелизм (21\%), подхват (19\%), анафора (18 \%), эпифора (10\%), синтаксическая тавтология (5\%), рамочная конструкция (4\%).

Вышеперечисленные виды синтаксического повтора выполняют следующие функции: эмфатическая (26 \%), эмоциональная (21\%), объединяюще-выделяющая (20 \%), перечисления (10\%), кульминационная (11\%), объясняюще-уточняющая (7 \%), последовательности (5\%). Следует отметить, что повторам практически во всех 